\title{
PHILOSOPHICAL STUDIES
}

Edited by WILFRID SELLARS and HERBERT FEIGL with the advice and assistance of PAUL MEEHL, JOHN HOSPERS, MAY BRODBECK

VOLUME VI

Contents October 1955

NUMBER 5

Pragmatism and the Verifiability Theory of Meaning by William P. Alston, UNIVERSTTY OF MICHIGAN

Irrationality and Insanity by Brian O'Shaughnessy,

KING'S COLLEGE, LONDON

'Possible' and Logical Absolutism by Herbert Hochberg,

NORTHWESTERN UNIVERSITY

Dispositional Properties and Dispositions by Gustav Bergmann, STATE UNIVERSTTY OF IOWA

\section{Pragmatism and the Verifiability Theory of Meaning \\ by WILLIAM P. ALSTON \\ UNIVERSITY OF MICHIGAN}

Pragmatrsm has long been thought of as providing aid and comfort for the philosophic attitude which would require of any cognitively meaningful statement that it be capable of empirical verification. Although represented by William James as an agency of reconciliation between the tough and the tender minded, it has often been found in the vanguard of the logical positivists, logical empiricists, scientific empiricists, and other partisans of the meter reading. Nor is that fountainhead of things pragmatic and pragmaticistic, Charles Sanders Peirce, excluded from the scope of this 
association. In fact it has become rather common in certain circles to regard Peirce's Pragmatic Principle as little more than an early, and rather crude, version of the Verifiability Theory of Meaning. For example, Justus Buchler states Peirce's pragmatism "concisely" as follows: "only those statements are genuinely synthetic which have sensible or experimental, i.e., confirmable, consequences." 1 And, again, "the meaning of a synthetic sentence is its pragmatic interpretant," and a pragmatic interpretant is "a formula for the entire class of confirmable consequences of a statement." 2

There is no doubt that an interpretation of this sort finds considerable support in Peirce's writings. In the first place, many of Peirce's formulations of what came to be called the Principle of Pragmatism are explicitly framed as interpretations of the meaning of a verbal expression, or of the import of a concept, in terms of the empirically discriminable consequences of certain actions. ${ }^{3}$ Consider the following statements of the principle:

"In order to ascertain the meaning of an intellectual conception one should consider what practical consequences might conceivably result by necessity from the truth of that conception; and the sum of these consequences will constitute the entire meaning of the conception." $(5.9)^{4}$

"If one can define accurately all the conceivable experimental phenomena which the affirmation or denial of a concept could imply, one will have therein a complete definition of the concept, and there is absolutely nothing more in it." (5.412)

"The total meaning of the predication of an intellectual concept is contained in an affirmation that, under all conceivable circumstances of a given kind ... the subject of the predication would behave in a certain way-that is, it would be true under given experiential circumstances ..." $(5.467)^{5}$

It is quite natural and proper that formulations of this sort should be translated into the form of a verifiability theory. For an assertion that a given line of action will have certain specifiable sensory results is the model of an empirically testable assertion; ${ }^{6}$ and so to say that the meaning of any statement consists of such assertions is to say that it consists of verifiable consequences.

A second support for this interpretation is to be found in some of the statements Peirce makes about the origin or basis of pragmatism. For example, he speaks in one place of pragmatism as having its origin in a laboratory mode of thinking or experimentalist temper of mind, which conditions a man so that "whatever assertion you may make to him, he will either understand as meaning that if a given prescription for an experiment ever can be and ever is carried out in act, an experience of a given description will result, or else he will see no sense at all in what you say." (5.411; cf. also 5.465) Finally some of the applications he makes of 
the principle have the true positivistic ring, for example, his contention that "it is foolish for Catholics and Protestants to fancy themselves in disagreement about the elements of the sacrament, if they agree in regard to all their sensible effects, here and hereafter" (5.401), and his contention that "if we know what the effects of force are, we are acquainted with every fact which is implied in saying that a force exists, and there is nothing more to know" (5.404).

This verifiability interpretation would thus seem unassailable, were it not that some of the formulations of the Principle of Pragmatism are couched rather differently, and in a way which makes it more intelligible that the principle should be called "pragmatic." They are built around the notion of practical bearing or relevance to action. They assert, to put it succinctly, that the meaning of a concept or cognitive expression is to be found by considering the practically relevant features of its object-i.e., the features which might be taken account of in acting with respect to the object. The initial statement of the principle in the article of 1878, "How to Make Our Ideas Clear," is of this sort: "Consider what effects, that might conceivably have practical bearing, we conceive the object of our conception to have. Then, our conception of these effects is the whole of our conception of the object." (5.402)

Other examples of this mode of formulation are the following:

"The entire intellectual purport of any symbol consists in the total of all general modes of rational conduct which, conditionally upon all the possible different circumstances and desires, would ensue upon the acceptance of the symbol." (5.438)

"A conception can have no logical effect or import differing from that of a second conception except so far as, taken in connection with other conceptions and intentions, it might conceivably modify our practical conduct differently from that second conception." (5.196)

"Pragmatism is the doctrine that every conception is a conception of conceivable practical effects ..." (5.196)

We shall call this the practicalist ${ }^{\tau}$ principle, and the version cited earlier the experimentalist principle. The terms 'pragmatism' and 'pragmatic principle' will be employed in a more general sense, so that the two principles just mentioned will be considered as alternative formulations of the Pragmatic Principle (although, as we are going on to argue, not alternatives on the same level).

We can further point up the difference between these two formulations by examining the schema which each would use in explicating the meaning of a statement. The experimentalist finds the key to the meaning of a statement in the sensory results which it implicitly predicts. Hence he would interpret a statement of the form ' $\mathrm{x}$ is $\mathrm{P}$ ' by providing a series of 
interpretants 8 of the form (A) 'If you do $m$ to $x$, then you will experience n.' The practicalist, on the other hand, in concentrating directly on relevance to deliberate conduct, finds the meaning of a statement by considering the ways it directs us to act toward an object when we desire certain results. Hence his interpretation of ' $x$ is $P$ ' will be couched in statements of the form (B) 'If you want $I$, then you ought to do $s$ to $x$.' For example, the experimentalist would translate 'This is a bell' into a series of statements such as: 'If you strike this, you will experience a ringing sound.' Whereas the practicalist would employ in his translation statements like 'If you want to hear a ringing sound, you ought to strike this.' It is evident that statements of the first sort can always be transformed into those of the second sort, by simply (1) taking the experienced object as an object of desire and (2) taking the action which is the condition of the experience as the action to which one is obligated on the condition of having the desire. In terms of the above schemas, simply substitute ' $n$ ' for ' $r$ ' and ' $m$ ' for ' $s$.' But, as we shall argue in the sequel, the converse relation does not hold. Not all practicalist interpretants can be transformed into experimentalist ones.

We can also distinguish the two formulations in terms of the way in which each specifies the nonverbal states which are involved in belief. For the experimentalist it is expectations which play this role; for the practicalist it is rather habits of conduct. On the experimentalist principle, to believe that this is a bell is to expect that certain sensory results will follow certain actions; on the practicalist principle it is to be disposed to act in certain ways on condition of having certain motives. Again it seems evident that whenever there is a sensory expectation, there is also a corresponding disposition to perform the action which is expected to produce the sensory result provided that result be desired. But, as we shall be contending, the reverse is not true; there are dispositions to action to which no sensory expectations correspond.

The existence of the practicalist principle raises serious questions as to the adequacy of the positivistic interpretation. In order to answer these questions we must investigate the relative positions of the two formulations in the Peircean philosophy and the logical connections between them. It will be our contention that:

1. The practicalist principle occupies a more fundamental place in Peirce's thought.

2. The experimentalist principle is arrived at only by conjoining the practicalist principle with a theory of human motivation which is open to doubt, to say the least, and hence the positivistic tendency in Peirce is not, as is generally supposed, a necessary consequence of his initial pragmatic orientation. 
3. If a more liberal theory of motivation is substituted we get a pragmatic theory of meaning which presents a complexion quite different from that of any verifiability theory.

First as to the question of the relative priority. Buchler is typical of positivistically inclined interpreters in taking the experimentalist formulation to be the canonical statement and attempting to explain away the other as a later development, occasioned by extraneous influences from other pragmatists. $^{9}$ But there are at least two considerations which render this reading untenable. First, in Peirce's most typical method of justifying pragmatism it is the practicalist formulation which emerges first in the argument, and which then serves as ground for the assertion of the experimentalist thesis. For example, in introducing the principle for the first time in "How to Make Our Ideas Clear," Peirce argues roughly as follows: The sole function of thought is the production of belief, which in turn essentially consists of a habit of action. Since a conception is essentially an element of thought it can refer to nothing unrelated to thought's function. Therefore the conception of any object is the conception of its "effects that might conceivably have practical bearings" (5.402), i.e., a conception of the object insofar as habitual modes of conduct might be directed on it. The experimentalist formulation is then derived from this by a process of reasoning the nature of which will be examined below.

Essentially the same line of argument is found at the other end of Peirce's philosophical career in a fragment of 1908 , included in Volume $\mathrm{V}$ of the Collected Papers (5.546-548). There Peirce maintains that (1) an assertion consists in taking responsibility for some future line of conducti.e., disposing oneself to act in a certain way vis-à-vis future occurrences; (2) judgment is a kind of assertion; (3) no concept can exist apart from judgment; (4) hence a concept has its intellectual content through a bearing on conduct. And even in the last of his Lectures on Pragmatism (1903), where the pragmatic principle, conceived as the principle of abductive inference, is stated most unequivocally as a verifiability principle, Peirce makes its adequacy as a criterion of abductive inference to depend on the supposition that nothing but "possibly practical considerations"-i.e., considerations of what is relevant to purposive action-have "any logical effect or import whatever." (5.196)

The second consideration which makes the claim of priority for the experimentalist formulation untenable is this. When Peirce came late in life to restate pragmatism in terms of his general theory of signs he does so by raising the question What is the ultimate logical interpretant of a sign? (5.476) In other words, what is there in the interpreter of a sign which constitutes his understanding of the sign? The answer to this question that would reflect the experimentalist formulation-viz., that the ulti- 
mate logical interpretant is an expectation of sensory results-is rejected in favor of one which reflects the practicalist formulation-viz., that the ultimate logical interpretant is a habit or a habit change.

If the practicalist formulation is the more basic in the order of Peirce's thought and the experimentalist formulation derived from it, how does this derivation take place? That it represents no mere analysis or restatement, but requires an additional premise, appears plainly in the following passage from "How to Make Our Ideas Clear." Having argued that the sole function of thought is to produce habits of action, Peirce goes on to say "What the habit is depends on when and how it causes us to act. As for the when, every stimulus to action is derived from perception; as for the how, every purpose of action is to produce some sensible result. . . ." (5.400) And continuing the discussion, in speaking of the concept of wine: "The occasion of such action would be some sensible perception, the motive of it to produce some sensible result. Thus our action has exclusive reference to what affects the senses, our habit has the same bearing as our action, our belief the same as our habit, our conception the same as our belief; and we can consequently mean nothing by wine but what has certain effects, direct or indirect, upon our senses." (5.401)

It is apparent from these passages how the transition takes place. The basis of the whole position, let us recall, is the conviction that the meaning of a cognitive sign is to be explicated in terms of the practically relevant aspects of its object. But what aspects of an object are practically relevant? Obviously those which our aims in dealing with the object would lead us to take account of. The discrimination of practically relevant aspects thus depends on an assessment of the aims of human action. It is at this point that Peirce introduces the crucial assumption that every deliberate action aims at producing some sensory experience or experiences. Grant this theory of motivation and it follows that only those characteristics of an object which will influence the sensations resulting from actions directed to that object can have any practical relevance, and hence that our conception of an object will be concerned exclusively with such characteristics as will be manifested in sensory experience. If we can cognitively refer to an object only with respect to what might appropriately be considered in action, and if all actions are directed to the production of sensations of one kind or another, it is evident that any cognitive expression has to do solely with the sensory potential of its object, and that our thought of any object will consist in supposing that "certain lines of conduct will entail certain kinds of inevitable experiences." (5.9)

That this line of argument is not confined to the 1878 period is shown by the reasoning preceding another expression of the experimentalist formulation, contained in a paper written 27 years later, which sums up 
the whole matter succinctly: "A conception, that is, the rational purport of a word or other expression, lies exclusively in its conceivable bearing upon the conduct of life; so that, since obviously nothing that might not result from experiment can have any direct bearing upon conduct, if one can define accurately all the experimental phenomena which the affirmation or denial of a concept could imply, one will have therein a complete definition of the concept, and there is absolutely nothing more in it." (5.412. First underlining mine. Cf. also 5.427.) It is also worthy of note that in the argument of the contemporary logical empiricist who bases the verifiability theory of meaning most squarely on pragmatic considerations, the late Hans Reichenbach, an analogous crucial assumption seems to be involved. ${ }^{10}$

Thus the experimentalist principle which seems so characteristic of Peirce only follows from its practicalist basis provided we assume all action to be motivated by aims at certain sorts of sensory states. A defense of Peirce on this point would require a more cogent support for this theory of motivation than it has yet received.

Received January 24, 1955

\section{NOTES}

${ }^{1}$ Justus Buchler, Charles Peirce's Empiricism (London: Kegan Paul, Trench, Trubner, \& Co., Ltd., 1939), p. 119.

${ }^{2}$ Ibid.

${ }^{3}$ Most of Peirce's formulations of the principle are concerned with the content or 'meaning' of concepts. See, for example, 5.9, 5.196, 5.402, 5.412. (All references to the writings of Peirce are to Collected Papers of Charles Sanders Peirce, edited by Charles Hartshorne and Paul Weiss (Cambridge, Mass.: Harvard University Press, 1931-1935), and are given in the standard way by specifying the volume and paragraph numbers.) Less often the principle is stated in terms of the meaning of verbal expressions, especially statements. See, for example, 5.18, 5.438, 5.467. These two modes of statement are not radically different for Peirce, since for him all thought is symbolic (5.421), and a concept functions as the meaning (in Peircean terms, the "interpretant") of a verbal expression. (5.412) Hence, for any statement about the "import" or "meaning" of a concept there is an equivalent statement about the meaning of a verbal expression.

* "Now this sort of consideration, namely, that certain lines of conduct will entail certain kinds of inevitable experiences is what is called a "practical consideration'." (5.9)

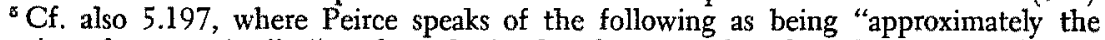
doctrine of pragmatism": "any hypothesis, therefore, may be admissible, in the absence of any special reasons to the contrary, provided it be capable of experimental verification, and only insofar as it is capable of such verification."

${ }^{n}$ It is analogous to what C. I. Lewis calls a terminating judgment.

7 It is true that Peirce explicitly rejected this term (5.412), but I am not using it with any of the Kantian connotations which were in Peirce's mind and which motivated his rejection.

${ }^{8}$ Following Peirce, we shall use the term 'interpretant' to refer to any sign which has the function of interpreting, explicating, or developing the meaning of another sign.

${ }^{8}$ Buchler, op. cit., pp. 154-55.

${ }^{10}$ See Experience and Prediction (Chicago: University of Chicago Press, 1938), Chap. I, esp. pp. 64-68. 